\title{
URETROSTOMIA PERINEAL EM FELINO - RELATO DE CASO
}

Ítalo Sena Carvalho ${ }^{1}$; Nadson Fernandes de Castro²; Úrsula Myleide Leal de Jesus ${ }^{3}$; Paloma Brito Teixeira ${ }^{4}$; Esther Lourenço Lelis ${ }^{4}$.

${ }^{1}$ Médico Veterinário graduado pela Universidade Federal do Piauí (UFPI), Bom Jesus-PI, Brasil. Médico Veterinário na Clínica Veterinária Paixão, Santa Maria/Brasília-DF, Brasil. Aprimorando em Técnica Cirúrgica de Pequenos Animais CETAC VET - São Paulo-SP, Brasil.

E-mail: italo.med.vet@gmail.com

${ }^{2}$ Médico Veterinário. Residência em Anestesiologia Veterinária pela Faculdade União

Pioneira de Integração Social-UPIS, Brasília-DF, Brasil. Mestre em Anestesiologia

Pela Escola Paulista de Medicina.

${ }^{3}$ Graduanda em medicina Veterinária no Centro Universitário do Planalto Central

Aparecido dos Santos - UNICEPLAC, Gama-DF, Brasil.

${ }^{4}$ Graduação em Medicina Veterinária e Pós-Graduação em Clínica Médica e Cirúrgica de Pequenos Animais pelo Centro Universitário de Desenvolvimento do Centro-Oeste - UNIDESC, Luziânia-GO, Brasil.

\section{Recebido em: 15/05/2020 - Aprovado em: 15/06/2020 - Publicado em: 30/06/2020 DOI: 10.18677/EnciBio_2020B45}

\begin{abstract}
RESUMO
O objetivo desse trabalho é relatar um caso de uretrostomia perineal em um felino macho, castrado, de um ano e quatro meses de idade, com quadro recidivante de obstrução uretral por cistite idiopática felina (CIF). A uretrostomia perineal no felino, tem como principais indicações nos casos de recidiva da obstrução uretral que não pode ser eliminada por cateterização, bem como para tratamento de estenoses secundárias à obstrução uretral e à sondagem da uretra, e ainda em casos de necrose distal do pênis. O paciente deu entrada na clínica veterinária Valpets, de Valparaíso-GO, com histórico de disquesia, anúria, apatia e vômito havia três dias. Foi observado dispneia, apatia, hálito urêmico, desidratação de aproximadamente $5 \%$, abdômen tenso e com sensibilidade dolorosa, bexiga repleta, rígida. Realizouse desobstrução uretral do paciente e o mesmo foi internado. Foram administrados analgésico, antiácido, antiemético e antibiótico, bem como fluidoterapia para reposição volêmica. Realizou-se exame hematológico, bioquímica sérica, urinálise e ultrassonografia. As alterações mais relevantes foram o valor da creatinina de 10,24 $\mathrm{mg} / \mathrm{dL}$ (referência $0,5-1,5$ ); dilatação da pelve renal e hemoglobinúria/proteinúria. $\mathrm{O}$ paciente permaneceu quatro dias internado e foi liberado após recuperação do quadro clínico. Após 34 dias o paciente teve recidiva e foi internado para estabilização. Decidiu-se realizar uretrostomia perineal. Tal conduta foi adequada para reestabelecimento do fluxo urinário do paciente em questão.
\end{abstract}

PALAVRAS-CHAVE: cirurgia, DTUIF, gato, uretra. 


\title{
PERINEAL URETHROSTOMY IN FELINE - CASE REPORT
}

\begin{abstract}
The objective of this work is to relate a case of perineal urethrostomy in a male cat, castrated, one year and four months old, with a recurrence of urethral obstruction due to feline idiopathic cystitis (ICF). Feline perineal urethrostomy has as its main indicators in cases of urethral obstruction that cannot be eliminated by catheterization, as well as for treatment of stenosis secondary to urethral obstruction and urethral catheterization, and even in cases of distal necrosis of the penis. The patient was admitted to the Valpets veterinary clinic, in Valparaíso-GO, with a history of dyskinesia, anuria, apathy and vomiting, for about three days. Dyspnea, apathy, uremic breath, approximately $5 \%$ dehydration, tense and painful abdomen, full, rigid bladder were observed. The patient's urethral clearance was performed and the patient was hospitalized. Painkillers, antacids, antiemetics and antibiotics were administered, as well as fluid therapy for volume replacement. Hematological examination, serum biochemistry, urinalysis and ultrasound were performed. The most relevant changes were the creatinine value of $10.24 \mathrm{mg} / \mathrm{dL}$ (reference 0.5 1.5); dilation of the renal pelvis and hemoglobinuria / proteinuria. The patient was hospitalized for four days and was discharged after recovery. After 34 days, the patient had a recurrence and was hospitalized for stabilization. It was decided to perform perineal urethrostomy. The stitches were removed after 14 days, during which time the wound was found in the remodeling phase. The adopted approach was adequate to reestablish the urinary flow of the patient in question.
\end{abstract}

KEYWORDS: surgery, cat, urethra.

\section{INTRODUÇÃO}

Uretrostomia é a criação de uma fístula permanente na uretra, que geralmente é realizada para constrições uretrais recorrentes ou irreparáveis, ou para evitar obstruções repetidas. Em gatos machos, a uretrostomia perineal é indicada para evitar a recidiva da obstrução ou para tratar a obstrução que não pode ser eliminada por cateterização, bem como para tratamento de estenoses secundárias à obstrução uretral e à sondagem da uretra (MACPHAIL, 2015).

Uma alteração que, quando recorrente, é indicativa de uretrostomia perineal, principalmente nos felinos machos, é a doença do trato inferior do felino (DTUIF). Esta é uma síndrome caracterizada pela manifestação de um ou mais sinais clínicos como polaciúria, hematúria, disúria/estrangúria, micção inapropriada e obstrução parcial ou total da uretra, que afeta cerca de $0,34 \%$ a $0,64 \%$ dos gatos machos (GRAUER, 2010). Sendo a cistite idiopática felina (CIF), a causa mais frequente de DTUIF. Outras causas menos comuns, tanto em machos quanto em fêmeas, incluem urólitos (principalmente de estruvita) e infecção primária do trato urinário (está com frequência rara em felinos), defeitos anatômicos, neoplasias, infecções do trato urinário e distúrbios neurológicos (CARVALHO, 2015).

Os gatos mais frequentemente acometidos incluem os machos, castrados, sedentários, obesos, com idade entre dois e sete anos, que vivem dentro de casa, consomem basicamente alimento balanceado seco e bebem pouca água. Além disso, fatores como confinamento sem acesso à rua, uso de vasilha sanitária, maior número de dias chuvosos no mês anterior ao aparecimento dos sinais clínicos e fatores de estresse também estão correlacionados ao aparecimento da DTUIF (COSTA, 2009). 
O diagnóstico de obstrução uretral por DTUIF baseia-se na história clínica (micção em locais incomuns, aumento da frequência de tentativas de micção), sendo confirmado através da palpação de uma bexiga grande, firme e tensa (BOJRAB; CONSTANTINESCU, 2005). Radiografia ou ultrassonografia e culturas de urina podem ser utilizadas para identificar a causa da obstrução (GRAUER, 2010).

As manobras de tratamento clínico para reestabelecimento do fluxo uretral incluem massagem peniana, cateterização uretral, retrohidropropulsão e compressão vesical na tentativa de deslocar o tampão uretral e urólitos. Porém, este procedimento pode levar, em alguns casos, à ruptura uretral iatrogênica (LEAL et al., 2012). Nos casos em que há recidiva frequente de obstrução por DTUIF ou quando não é possível a desobstrução uretral, mesmo sendo a primeira ocorrência desta patologia, o tratamento mais adequado é a uretrostomia perineal (MACPHAIL, 2015). Nesse sentido, o objetivo deste trabalho é relatar o tratamento de obstrução recorrente devido a DTUIF, em um felino de um ano e quatro meses de idade, através da uretrostomia perineal.

\section{RELATO DO CASO}

Deu entrada na clínica veterinária Valpets, de Valparaíso-GO, um felino, macho de um ano e quatro meses de idade, castrado, com histórico de disquesia, anúria, apatia e vômito havia três dias. À avaliação clínica, o paciente apresentava dispneia, apatia, hálito urêmico, desidratação e queda de pelo. À palpação, observou-se abdômen tenso, bexiga repleta, rígida, e o paciente demonstrava sinais de dor. Verificou-se frequência cardíaca de 188 batimentos por minuto, frequência respiratória de 46 movimentos por minuto, tempo de preenchimento capilar de 3 segundos, mucosas pouco pálidas, grau de desidratação de aproximadamente $5 \%$.

O paciente foi internado para tratamento da condição clínica em que se encontrava. Foram administradas medicações como dipirona $25 \mathrm{mg} / \mathrm{kg}$ a cada 12 horas por via subcutânea, ondansetrona $0,5 \mathrm{mg} / \mathrm{kg}$ a cada 8 horas por via endovenosa (EV), omeprazol $0,7 \mathrm{mg} / \mathrm{kg}$ a cada 12 horas $E V$, enrofloxacina $5 \mathrm{mg} / \mathrm{kg}$ a cada 12 horas SC. Além disso, foi realizada reposição volêmica - ringer com lactato numa taxa de infusão de $5 \mathrm{~mL} / \mathrm{kg} / \mathrm{hora}$. Realizou-se anestesia com propofol, na dose de $2 \mathrm{mg} / \mathrm{kg} \mathrm{IV}$, sondagem uretral, desobstrução e lavagem da vesícula urinária. Foram solicitados exames como hemograma, alanina aminotransferase $(\mathrm{ALT})$, aspartato aminotransferase (AST), ureia, creatinina, urinálise, ecografia abdominal. No hemograma, não houve alterações dignas de nota. $O$ valor sérico da creatinina foi de $10,24 \mathrm{mg} / \mathrm{dL}$ (referencia $0,5-1,5 \mathrm{mg} / \mathrm{dL}$ ); da ureia foi de $358 \mathrm{mg} / \mathrm{dL}$ (referência $15-40 \mathrm{mg} / \mathrm{dL}$ ). Os principais achados de urinálise foram coloração turva, proteinúria/hemoglobinúria. $\mathrm{Na}$ ultrassonografia abdominal foi observado espessamento da parede gástrica e da vesícula urinária, presença de sedimento urinário, bem como microcristais, uretra dilatada; discreta dilatação da pelve renal. Diante dessas alterações, fechou-se diagnóstico de DTUIF por cistite idiopática. O paciente permaneceu quatro dias internado e foi liberado após reestabelecimento do quadro de uremia.

Após 34 dias o paciente retornou com novo quadro de obstrução uretral. Ao exame o paciente apresentava-se em decúbito lateral, abdômen tenso e com sensibilidade dolorosa, bexiga repleta e tensa. Verificou-se frequência cardíaca de 150 batimentos por minuto, frequência respiratória de 36 movimentos por minuto, mucosas normocoradas, tempo de preenchimento capilar menor que dois segundos. Realizou-se o mesmo protocolo anestésico citado anteriormente, para desobstrução uretral e lavagem da vesícula urinária. 
Repetiu-se hemograma, onde verificou-se linfopenia e neutrofilia relativas, hiperhemoglobinemia. Além disso, foram realizados exames bioquímicos, onde foi observado creatinina de $4,59 \mathrm{mg} / \mathrm{dL}$ e ureia de $283 \mathrm{mg} / \mathrm{dL}$. Realizou-se novamente sedação para sondagem uretral, desobstrução e lavagem da vesícula urinária. $O$ paciente foi internado, a terapêutica adotada consistiu de reposição volêmica com ringer com lactato numa taxa de infusão de $5 \mathrm{~mL} / \mathrm{kg} / \mathrm{hora}$, dipirona $25 \mathrm{mg} / \mathrm{kg}$ a cada 12 horas por via subcutânea, ondansetrona $0,5 \mathrm{mg} / \mathrm{kg}$ a cada 8 horas por via endovenosa (EV), omeprazol $0,7 \mathrm{mg} / \mathrm{kg}$ a cada 12 horas $E V$, enrofloxacina $5 \mathrm{mg} / \mathrm{kg}$ a cada 12 horas SC, ranitidina $1 \mathrm{mg} / \mathrm{kg}$ a cada 12 horas SC. Após três dias de internação, sem sucesso no reestabelecimento do fluxo urinário, decidiu-se realizar uretrostomia perineal.

O protocolo anestésico consistiu de: medicação pré-anestésica - cetamina $(0,15 \mathrm{mg} / \mathrm{kg}, \mathrm{IM})$; indução anestésica - pré-oxigenação através de máscara com fluxo corrente em 2 L/minuto; indução com $1,5 \mathrm{v} \%$ de isoflurano; realização de bloqueio locorregional com bupivacaína $8 \%$ hiperbárica no volume de $0,5 \mathrm{~mL}$ através de punção sacro coccígea com agulha de quincke no 22G; manutenção anestésica foi realizada através da infusão contínua de propofol $0,15 \mathrm{mg} / \mathrm{kg} /$ minuto IV. Durante todo o procedimento cirúrgico foi administrado ringer com lactato na dose de 5 $\mathrm{mL} / \mathrm{kg} / \mathrm{hora}$ via intravenosa.

O procedimento cirúrgico foi realizado conforme a técnica descrita por Bojrab e Constantinescu, (2005), bem como por Macphail, (2015). Colocou-se sutura em bolsa de tabaco ao redor do ânus. Após previa assepsia da região operatória e colocação de panos de campo, realizou-se uma incisão elíptica ao redor do escroto e prepúcio; fazendo-se a amputação de ambos. Por meio de técnica de divulsão com tesoura de Metzenbaum, procedeu-se a Liberação do tecido circundante do pênis e a uretra distal em cada lado; Estendeu-se a dissecção ventral e lateralmente em direção à fixação do pênis e ao arco isquiático. Elevou-se o pênis dorsalmente e separou-se de modo penetrante o ligamento peniano ventral. Realizou-se secção dos músculos isquiocavernosos e isquiouretrais em suas inserções no ísquio, minimizando assim, a hemorragia e evitando lesão em ramos do nervo pudendo. Fez-se o rebatimento do pênis, ventralmente expondo a superfície dorsal. Em seguida, localizou-se as glândulas bulbouretrais. Removeu-se o músculo retrator do pênis. Realizou-se uma incisão longitudinal na uretra peniana, com lâmina de bisturi número 11; aumentou-se a incisão com tesoura de íris até próximo da uretra pélvica aproximadamente um centímetro além do nível das glândulas bulbouretrais. Em seguida, utilizando-se uma pinça hemostática de Halsted fechada por cima da uretra, verificou-se se a incisão provocou largura adequada na uretra. Ato contínuo foi a sutura da mucosa uretral à pele, com fio de nylon, calibre 4.0, em padrão de sutura interrompida simples. Em seguida, realizou-se amputação da porção distal terminal do pênis. Procedeu-se fechamento do restante da pele com fio de nylon, calibre 3.0, em padrão de sutura interrompida simples (figura 1).

O tratamento pós-operatório consistiu de norfloxacino $15 \mathrm{mg} / \mathrm{kg}$ a cada 12 horas por via oral (VO) durante 14 dias; meloxicam $0,05 \mathrm{mg} / \mathrm{kg}$ a cada 24 horas por via subcutânea (SC) durante cinco dias; dipirona $25 \mathrm{mg} / \mathrm{kg}$ a cada 12 horas SC durante cinco dias; cetamina $0,15 \mathrm{mg} / \mathrm{kg}$ a cada 4 horas SC durante quatro dias. $\mathrm{O}$ paciente permaneceu de frauda até a cicatrização total da ferida cirúrgica, sendo trocada e realizada lavagem com $\mathrm{NaCl} 0,9 \%$, sempre que necessário. Nos quatro primeiros dias de pós-operatório, houve inflamação com formação de hematoma ao redor da ferida cirúrgica (figura 2A). O controle de tal inflamação foi efetuado com uso de gel de massagem à base de escina, dimetilsulfóxido (DMSO), dexametasona, 
prednisolona, lidocaína $\left(\mathrm{DM}-\mathrm{Gel}^{\circledR}\right)$. Os pontos foram retirados 14 dias após o procedimento cirúrgico, a ferida encontrava-se em fase de remodelamento. Após 20 dias, a ferida estava totalmente cicatrizada (figura $2 \mathrm{~B}$ ).

FIGURA 1 - Aspecto final da uretrostomia (ainda com presença de hemorragia pósoperatória imediata esperada para o tipo de procedimento), realizada em um felino macho de um ano e quatro meses de idade.

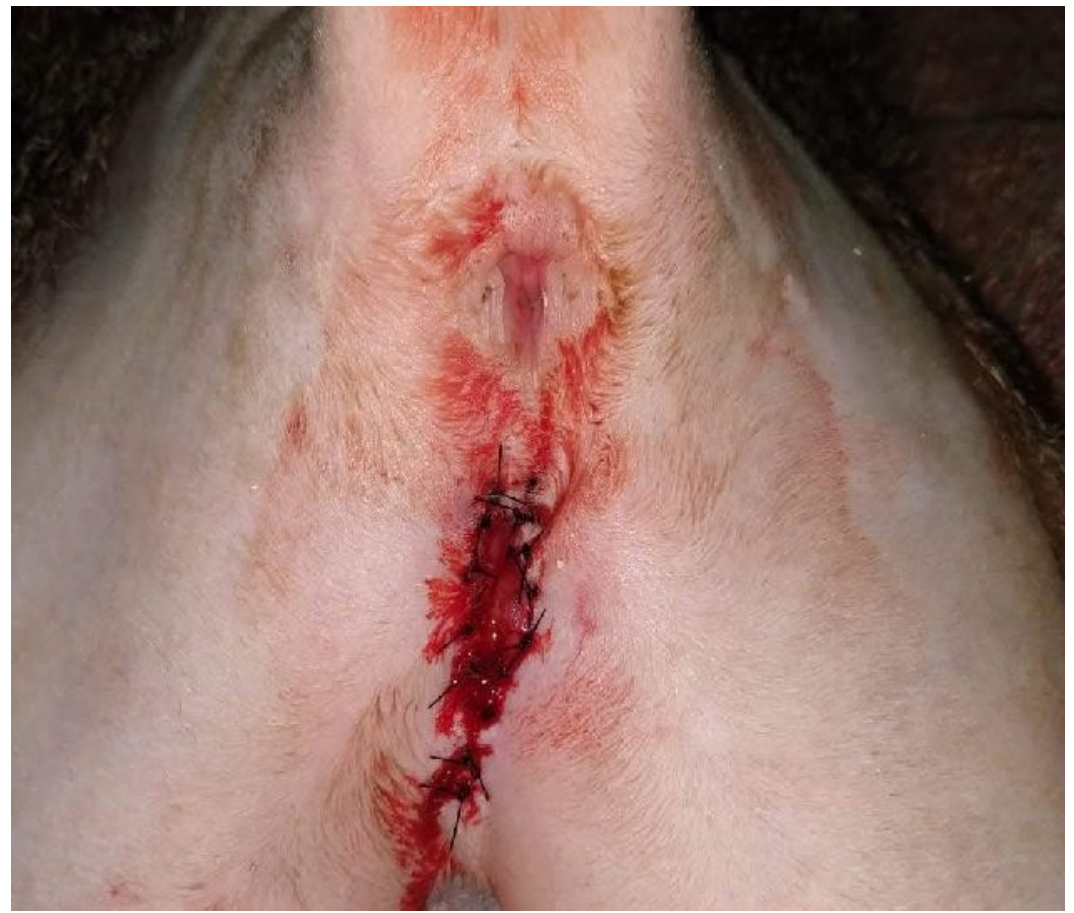

Fonte - M.V. Nadson Fernandes.

FIGURA 2 - Ferida cirúrgica (nos quatro primeiros dias após uretrostomia perineal) com presença de hematoma ao redor da mesma, bem como presença de secreção mucopurulenta, em um felino de um ano e quatro meses de idade (A). Aspecto da fístula uretral, 20 dias após uretrostomia (B).
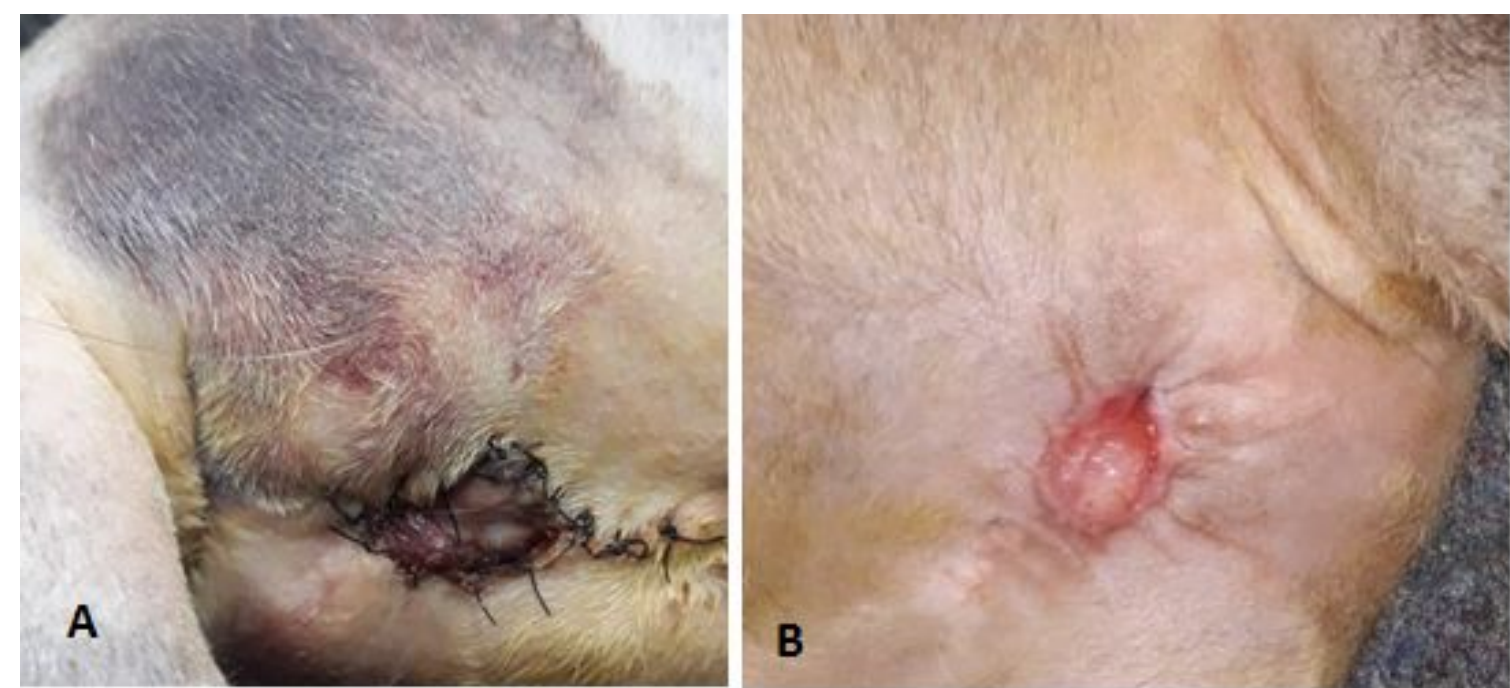

Fonte-Arquivo pessoal. 


\section{DISCUSSÃO}

Inúmeros são os fatores relacionados aos riscos dos felinos serem acometidos por DTUIF. Animais que vivem em ambientes confinados ou em grandes populações, gatos obesos, castrados, com dieta exclusivamente seca e expostos a diversos fatores que favoreçam o estresse, estão no grupo de risco de desenvolverem esta doença (GRAUER, 2010; LITTLE, 2016).

Felinos machos são mais susceptíveis à obstrução em relação às fêmeas, devido à conformação anatômica da uretra peniana extremamente estreita (HOSTUTLER et al., 2005). A obstrução uretral provocada por DTUIF está sendo relatada em um gato macho de um ano e quatro meses de idade, corroborando com Lima et al., (2007) e Neves et al., (2011), que observaram uma maior incidência de DTUIF em felinos machos do que nas fêmeas.

A doença do trato urinário inferior dos felinos (DTUIF) resulta em alterações da micção, sendo motivo frequente de consulta veterinária (XAVIER JÚNIOR et al., 2019). O paciente em questão foi levado para a consulta veterinária devido a alterações da micção, entre outras manifestações anteriormente comentadas.

Os pacientes com essa patologia, frequentemente apresenta recidiva e cronicidade (LEMBERGER et al., 2011). Para Grauer (2010), 30\% a 70\% dos pacientes acometidos com quadros de DTUIF, apresentarão recidivas. O paciente do presente estudo foi tratado clinicamente, mas apresentou recidiva do quadro de obstrução uretral por CIF.

Gatos com DTUIF podem manifestar periúria, hematúria, disúria, estrangúria, polaciúria, anúria, hiporexia ou anorexia, êmese, apatia, diarreia, isolamento, lambedura excessiva na região perineal e abdome caudal, podendo também manifestar comportamento de remoção de pelos da cauda; sendo que tais sinais podem ser intermitentes e apresentar recorrência com ou sem tratamento (CRIVELLENTI, 2015; DIBARTOLA, 2015). Outros sinais incluem prostração, distensão e dores abdominais (SILVA et al., 2017). O paciente do presente relato manifestou sinais como anúria, apatia, vômito e disquesia, que foram relatados pelo tutor, além disso, foi verificado prostração, distensão e dor abdominal (durante a avaliação do exame físico/clínico) e, hematúria durante a desobstrução uretral.

Pacientes com obstrução aguda do trato urinário inferior podem apresentar hidronefrose e hidroureter ligeiros (MARTINS, 2016). No paciente do presente estudo foi observado dilatação discreta da pelve renal, que é um achado da hidronefrose. Tal alteração poderia ter progredido, caso o paciente não tivesse sido trazido para tratamento do quadro de obstrução uretral, que estava provocando estase do fluxo de urina do ureter para a bexiga e consequentemente provocando dilatação da pelve renal.

Casos de obstrução uretral frequente por DTUIF ou quando não é possível a desobstrução uretral, mesmo sendo a primeira ocorrência desta patologia, o tratamento mais indicado é a uretrostomia perineal (MACPHAIL, 2015). O paciente do presente relato caracteriza um desses casos, uma vez que apresentou quadros repetidos de obstrução em função de cistite idiopática felina, necessitando da intervenção cirúrgica de uretrostomia perineal.

Algumas complicações podem ocorrer após o procedimento de uretrostomia perineal, tais como hemorragia pós-operatória, vazamento urinário subcutâneo, infecção, estenose uretral, incontinência urinária e fecal, bem como prolapso retal (BOJRAB; CONSTANTINESCU, 2005). A hemorragia pós-operatória foi minimizada através de técnica de sutura adequada, que deve ser realizada incluindo-se a mucosa da uretra e tecido cavernoso na sutura cutânea. A estenose uretral foi 
evitada realizando-se adequada abertura da uretra. A incontinência urinária e fecal foi evitada, não provocando lesão em ramos do nervo pudendo, através de cuidadosa manipulação dos tecidos durante o procedimento. A infecção foi evitada através de rigorosa limpeza da ferida, sempre que necessário, bem como utilização de antibioticoterapia.

A complicação ocorrida no paciente do presente relato foi a ocorrência de inflamação e hematoma ao redor da ferida, bem como presença de secreção mucopurulenta. Tais alterações foram controladas com uso de gel de massagem à base de escina, dimetilsulfóxido (DMSO), dexametasona, prednisolona, lidocaína $\left(D M-G e I^{\circledR}\right)$ e lavagem/limpeza frequente da ferida cirúrgica, respectivamente.

É importante ressaltar que o tratamento da DTUIF deve ser adotado de forma sistemática, envolvendo tratamento clínico associado ao tratamento cirúrgico (este quando necessário), além das medidas de manejo tanto nutricional quanto ambiental, para prevenção da recidiva. Hábitos de baixa ingestão de água (DEFAUW et al., 2011) principalmente quando associado à uma dieta predominantemente de ração seca, também são fatores de risco para a CIF (OLIVEIRA et al., 2015). Algumas medidas tais como manutenção das bandejas sanitárias sempre limpas e secas, distantes da água e do alimento e, assim como para as vasilhas de água e comida, deve-se evitar colocá-las em lugares barulhentos ou excessivamente expostos (CRIVELLENTI, 2015), onde os gatos não sejam ameaçados ou assustados por outros animais, movimentos repentinos, duto de ar ou qualquer aparelho que possa começar a funcionar inesperadamente enquanto o animal está comendo ou bebendo (BUFFINGTON, 2011).

\section{CONCLUSÕES}

A uretrostomia perineal, com amputação do pênis, é uma técnica cirúrgica efetiva para reestabelecimento do fluxo urinário em felino obstruído que não respondem ao tratamento clínico. O quadro de obstrução uretral recorrente do paciente deste relato foi tratado adequadamente com esta técnica.

É de extrema importância que o clínico veterinário esclareça aos tutores a importância da manutenção das mudanças no manejo do animal tais como manter sempre água limpa e fresca à vontade, em locais que o animal não se recuse ir à vasilha de água com frequência, não adotar dieta totalmente seca e manter bandeja sanitária sempre disponível, com areia própria para gato. Tais medidas servem tanto para gatos que tiveram DTUIF, bem como para evitar que essa afecção ocorra nos animais que nunca foram acometidos.

\section{REFERÊNCIAS}

BOJRAB, M. J.; CONSTANTINESCU, G. M. Tratamento da obstrução uretral no gato. In: BOJRAB, M. J. Técnicas atuais em cirurgia de pequenos animais. $5^{\text {a }}$ ed. São Paulo: Roca, 2005, Pag. 363-368.

BUFFINGTON, C. A. T. Idiopathic vystitis in domestic cats - Beyond the lower urinary tract. Journal of Veterinary Internal Medicine. 25, 784-796, 2011. Disponível em: <https://www.ncbi.nlm.nih.gov/pmc/articles/PMC3760680>. doi: 10.1111/j.1939-1676.2011.0732. Acesso em 23 de maio de 2020.

CARVALHO, Y. M. Apoio nutricional ao tratamento das urolitíases em gatos. In: JERICÓ, M. M.; KOGIKA, M. M.; ANDRADE NETO, J. P. Tratado de medicina interna de cães e gatos. Rio de Janeiro: Roca, 2015. Cap. 42. 
COSTA, F. V. A. Contribuição ao estudo da doença do trato urinário inferior felino (DTUIF) - Revisão de literatura. Medvep - Revista Científica de Medicina Veterinária - Pequenos Animais e Animais de Estimação. 7(23); 448-463. 2009. Disponível em: <http://www.medvep.com.br/wpcontent/uploads/2016/04/Artigo225.pdf>. Acesso em 23 de maio de 2020.

CRIVELLENTI, L. Z. Nefrologia e urologia. In: CRIVELLENTI, L. Z.; CRIVELLENTI, S. B. (eds.) Casos de rotina em medicina veterinária de pequenos animais. São Paulo, Medvet, 2015. CAP. 11. PAG. 419-486.

DIBARTOLA, S.P. Cistite idiopática obstrutiva e não obstrutiva. In: NELSON, R.W.; COUTO, C.G. Medicina interna de pequenos animais. $5^{\underline{a}}$ ed. Rio de Janeiro: Elsevier, 2015. p.698-703.

GRAUER, G. F. D. Doença do trato urinário inferior dos felinos. In: NELSON, R. W.; COUTO, C. G. Medicina interna de pequenos animais. Rio de Janeiro, Elsevier, 2010. Cap. 47. Pag. 680-686.

HOSTUTLER, R. A.; CHEW, D. J., DIBARTOLA.; S. P. Recent Concepts in Feline Lower Urinary Tract Disease. Veterinary Clinics Small Animal Practice, v.35, p.147-170, 2005. Disponível em:<https://pubmed.ncbi.nlm.nih.gov/15627632>. doi: 10.1016/j.cvsm.2004.08.006. acesso em 23 de maio de 2020.

LEAL, L. M.; CRIVELENTI, L. Z.; CIPOLLI, V. M. M.; LIMA, T. B.; MORATO, G. O.; MORAES, P. C. Uretrostomia pré-púbica após ruptura uretral em felino com doença do trato urinário inferior. Clínica Veterinária, ano XVII, n. 97, p. 100-104, 2012.

LEMBERGER, S. I. K.; DORSCH, R.; HAUCK, S. M.; AMANN, B.; HIRMER, S.; et al. Decrease of Trefoil factor 2 in cats with feline idiopathic cystitis. British Journal of Urology International, v.107, n.4, p.670-677, 2011. Disponível em: https://translate.google.com/translate?hl=pt-

BR\&sl=en\&u=https://europepmc.org/article/med/20636394\&prev=search>. $\quad$ doi: 10.1111/j.1464-410x.2010.09500. Acesso em 24 de maio de 2020.

LIMA, E. R..; REIS, J. C.; ALMEIDA, E. I.; MOURA, R. T. D.; CAVALCANTI, V. F.; et al. Doença do trato urinário inferior em gatos domésticos (Felis domesticus, Linnaeus, 1758), atendidos no hospital veterinário da universidade federal rural de pernambuco. Ciência veterinária dos trópicos. v. 10, n. 2/3, p. $113-118,2007$. Disponível em:<http://www.rcvt.org.br/volume10_2_3/113-118.pdf>. Acesso em 23 de maio de 2020.

LITTLE, S. E. Trato Urinário Inferior. In: LITTLE. S. E. O Gato - Medicina Interna. Rio de Janeiro: Rocca, 1 ed. 2016. Cap. 4, p. $944-975$.

MACPHAIL, M. C. Cirurgia da bexiga e da uretra. In: FOSSUN, T. W. Cirurgia de pequenos animais. Rio de Janeiro: Elsevier, 2015. Cap. 26, pag. 735-779.

MARTINS, A. A. D. Caracterização da apresentação clínica da uropatia obstrutiva felina: sinais clínicos e alterações laboratoriais e imaginológicas em 20 pacientes. 100 f. Dissertação (Mestrado), Universidade Lusófona de 
Humanidades e Tecnologias Faculdade de Medicina Veterinária Lisboa 2016. Disponível em:<http://hdl.handle.net/10437/7608>. Acesso em 23 de maio de 2020.

NEVES, L.; WANDERLEY, M. C.; PAZZINI, J. Doença do trato urinário em gatos (Felis catus domesticus, LINNAEUS, 1758) atendidos em clínicas veterinárias da região de Ribeirão Preto-SP. Nucleus Animalium. v.3,n.1,maio 2011. Disponível em:< http://www.nucleus.feituverava.com.br/index.php/animalium/article/view/571.>. DOI: 10.3738/1982.2278.571. Acesso em 23 de maio de 2020.

SILVA, E. B.; BABO, A. M. S.; CORREA, J. M. X.; LAVOR, M. S. L. Correção de estenose uretral após uretrostomia em gato - Relato de caso. Veterinária. e Zootecnia. 24(3); p. 504-508, 2017. Disponível em: $<$ https://rvz.emnuvens.com.br/rvz/article/view/275>.

DOI: https://doi.org/10.35172/rvz.2017.v24.275. Acesso em 23 de maio de 2020.

XAVIER JÚNIOR, F. A. F.; DUTRA, M. S.; FREITAS, M. M.; MORAIS, G. B.; VIANA, D. A.; et al. A cistite idiopática felina: o que devemos saber. Ciência Animal, v.29, n.1, p.63-82, 2019. Disponível em: < http://www.uece.br/cienciaanimal/dmdocuments/06.\%20Ci\%C3\%AAncia\%20Animal, \%20v.29,\%20n.1,\%20p.63-82,\%202019..pdf. >. Acesso em 23 de maio de 2020. 